Original Research Paper

\title{
Study the Impact of T-helper 1 Cytokine (TNF- $\alpha$ ) Polymorphisms on Susceptibility/Resistance to Brucellosis in Makkah Region
}

\author{
${ }^{1,2}$ Alaa B. Ismael, ${ }^{1,3}$ Adil Mergani, ${ }^{4,5}$ Salama A-H Mostafa and ${ }^{4}$ Abdelmoneim M. Salim \\ ${ }^{I}$ Department of Medical Biotechnology, Faculty of Applied Medical Sciences, Taif University, Turrabah, 21995, KSA \\ ${ }^{2}$ Department of Animal Medicine, Faculty of Veterinary Medicine, Zagazig University, Zagazig 44519, Egypt \\ ${ }^{3}$ Department of Human Molecular Genetics, National Cancer Institute (NCI), Gezira University, Sudan \\ ${ }^{4}$ Department of Medical Microbiology, Faculty of Applied Medical Sciences, Taif University, Turabah, 21995, KSA \\ ${ }^{5}$ Immunobiology and Immunopharmacology Unit, Animal Reproduction Research Institute (ARRI), Giza, Egypt
}

\author{
Article history \\ Received: 18-05-2016 \\ Revised: 07-08-2016 \\ Accepted: 09-08-2016 \\ Corresponding Author: \\ Alaa B. Ismael and \\ Adil Mergani \\ Department of Medical \\ Biotechnology, Faculty of \\ Applied Medical Sciences, Taif \\ University, Turrabah, 21995, \\ KSA \\ Email: a.alahmar@tu.edu.sa, \\ alismael7@gmail.com
}

\begin{abstract}
Polymorphisms in the regulatory regions of cytokine genes may not only increase susceptibility to some infectious diseases but also affect the course and prognosis of the disease. TNF- $\alpha$ is considered an important Th1 cytokines that plays critical roles in control of Brucella infection and in macrophage activation. In this study, we are going to analyze the relationship of two polymorphisms in TNF- $\alpha$ and the inherited susceptibility/resistance to brucellosis in population of Makkah region. A cases-control association study was conducted in 69 individuals with human Brucellosis and 112 healthy individuals. Genotyping of TNF- 308G $>\mathrm{A}$ and $-857 \mathrm{C}>\mathrm{T}$ polymorphism in both patients and healthy controls was done by PCR-RFLP method and were assessed for potential associations with susceptibility for human brucellosis and their mode of penetrance. The findings indicate an increased risk of TNF- $\alpha-308$ A allele for human brucellosis reliable with the recessive genetic model of penetrance (Odd Ratio: 3.222, 95\% CI: $1.008-5.702, \mathrm{P}=0.018$ ). There is no association between susceptibility of human brucellosis and TNF- $\alpha-857 \mathrm{C} / \mathrm{T}$ polymorphism was observed. The protective role of TNF- $\alpha-857 \mathrm{C} / \mathrm{T}$ polymorphism against human brucellosis in this study population could not be excluded.
\end{abstract}

Keywords: Brucellosis, Tumor Necrosis Factor-Alpha, Polymorphism

\section{Introduction}

Brucella species are Gram negative, facultative intracellular bacteria that cause abortion and temporary infertility in domestic animals (cattle, goats, sheep and camel) and undulant fever, arthritis, osteomyelitis and endocarditis in humans (Benjamin and Annobil, 1992; Corbel, 1997). Brucellosis is an endemic disease, mainly in Middle East, Africa, Asia and Central and South America and continues to execute significant health problems and important economic losses (Pappas, 2007). In Saudi Arabia, although human cases of brucellosis were reported sporadically between 1956 and 1982, brucellosis has emerged as a major public health problem in early 1980s with increasing rates of annual admissions for brucellosis (Kambal et al., 1983; Madkour et al., 1985; Arrighi, 1986). This increasing in incidence rates of brucellosis has been strongly linked to the uncontrolled importation of potentially infected animals with brucellosis, the prevailing habit of ingesting raw milk or its products among the population with a nomadic background and widespread cattle breeding (Hafez, 1986).

There are four Brucella species that cause disease in humans; B. melitensis, B. suis, B. abortus and B. canis, in descending order of pathogenicity. Transmission of the disease to humans occurs through direct contact with infected animal parts, the consumption of infected, unpasteurized milk products and inhalation of infected aerosolized particles. Brucella invade the reticuloendothelial cells and can be sequestered in macrophages at specific locations within the body, such as spleen, brain, joints, heart, liver and bone marrow (Ficht, 2003). Innate immunity recognition receptors can detect components so-called Pathogen-Associated Molecular Patterns (PAMPs) to provoke a host 
protective response (Janeway Jr and Medzhitov, 2002). Human protective immune response against Brucella infection depends on cell-mediated immunity. This involves mainly activated antigen-presenting cells (dendritic cells, macrophages) and CD4+, CD8+ T lymphocytes. This is mediated by a Th1 immune response and is considered to be critical for the efficiency of the protective anti-Brucella immune response (Zhan et al., 1993; Rodriguez-Zapata et al., 2010). The activated host antigen-presenting cells release interleukin-12 (IL-12), which causes the differentiation of Th0 cells into Th1 cells that secrete gamma interferon (IFN- $\gamma$ ) and up-regulates macrophage killing mechanisms. This action is realized by induction of hydrogen peroxide and superoxide anions (Huang et al., 2005; Murphy et al., 2001). In addition, CD8+ cytotoxic $\mathrm{T}$ cells that secrete IFN- $\gamma$ are able to lysis $B$. abortus infected macrophages. This T-cell subpopulation is critical for protection against Brucella infection (Oliveira and Splitter, 1995). Besides environmental and pathogen factors, it is generally accepted that host genetic factors are major determinants of susceptibility to or outcome of infectious diseases in humans. Target gene studies have implicated several immunogenetic polymorphisms in human infectious diseases, cytokine genes and HLA being the most relevant ones (Adrian and Hill, 1998). Polymorphisms in the regulatory regions of cytokine genes may not only increase susceptibility to some infectious diseases but also affect the course and prognosis of the disease (Bidwell et al., 1999; Bidwell et al., 2001). Several studies reported an association between cytokine genes polymorphism and development of brucellosis. Two of the most important Th1 cytokines are TNF- $\alpha$ and IFN- $\gamma$, both play critical roles in control of Brucella infection and in macrophage activation (Jiang, 1993; Baldwin and Parent, 2002; Dornand et al., 2002).

TNF- $\alpha$ is a pro-inflammatory cytokine that is activated during the acute phase immune response to extracellular pathogens. TNF- $\alpha$ production appears to be necessary for full expression for macrophage antibrucella activity (Jiang et al., 1993). Studies in susceptible mice model established that effective control of brucellosis is relies on TNF- $\alpha$ as well as CD8+ T cells until IFN- $\gamma$ production resumed and clearance initiated (Baldwin and Parent, 2002). In addition to, being important in resistance to brucella, TNF- $\alpha$ may be associated with immunopathology of the disease, depending on the timing (Caballero et al., 2000a). Genetic polymorphisms that affect production levels of certain cytokines may determine the severity, risk or protection in some infectious diseases like brucellosis. In this study, we are going to analyze the relation of the well characterized TNF- $\alpha$ polymorphisms and the association with the alteration in cytokine expression level, immune responses and predisposition/resistance to human brucellosis among population of Makkah region.

\section{Materials and Methods}

\section{Study Design and Selection of Patients and their Controls}

A case-control prospective study was carried out to investigate the impact of Th-1 cytokine, TNF- $\alpha$, polymorphisms on resistance/susceptibility to human brucellosis disease among Saudi population at Makkah region. All patients who have recruited to general hospitals during the period of study subject selection and are presenting with clinical signs and symptoms (e.g., fever, malaise, night sweating, weakness, weight loss, myalgia, splenomegaly, lymphadenophathy and arthralgia), suggestive of active brucellosis. They had been examined by specialist and confirmed by a positive serological test in a single high titers $(\geq 1 / 160)$ of Standard Agglutination Test (SAT) and/or positive blood cultures. They were selected, after their acceptance to participate in the study. A group of controls composed of healthy individuals with no history of brucellosis or genetic disorders. They are matching for geographic area, age and sex and have the same backgrounds as the cases. They are at the same risk of exposure for brucellosis and have SAT $\leq 1 / 80$. They were selected for the study after accepting to participate in the study.

\section{Screening of TNF- $\alpha$ Promoter Polymorphisms by PCR-Restriction Fragment Length Polymorphism (PCR-RFLP)}

Genomic DNA was extracted from peripheral blood leukocytes using standard methods as described by the manufacture (Micromix660 DNA extraction kit, Talent, Italy). Two well characterized Single Nucleotide Polymorphisms (SNPs) in the TNF- $\alpha$ promoter region were screened in this study. One of them is transition replacement of adenine for guanine at positions -308 and the second polymorphism is transition replacement of thymine for cytosine at position -857 . All PCR reactions were run under conditions previously described (Fargion et al., 2001; Soga et al., 2003). Primer sequences for the polymorphism at position 857(rs1799724) are sense 5'-AAG TCG AGT ATG GGG ACC CCC CGT TAA-3' and anti-sense 5'-CCC CAG TGT GTG GCC ATA TCT TCT T-3', those for the gene polymorphism at position -308 (rs361525) are forward 5'-GGG ACA CAC AAG CAT CAA GG-3' and reverse 5'-GGG ACA CAC AAG CAT CAA GG-3'.

DNA samples were PCR amplified in $25-\mu \mathrm{L}$ total volume containing $200 \mu \mathrm{mol} / \mathrm{l}$ deoxynucleoside triphosphate, $10 \mu \mathrm{mol} / 1$ each primer, $1.5-\mathrm{mmol} / 1$ magnesium chloride, a $2-\mu \mathrm{L}$ DNA sample and $2 \mathrm{U}$ of Taq polymerase. Then, in a total volume of $15 \mu \mathrm{L}$, two 
$\mu \mathrm{L}$ PCR products were digested overnight at $37^{\circ} \mathrm{C}$ with Hinc II to detect the SNP at position -857 and at $37^{\circ} \mathrm{C}$ with NcoI to detect the SNP in the -308 gene allele. The Digested DNA was loaded on a $8 \%$ Non-denaturaning polyacrylamide gel (SeaKemÒ GTGÒ agarose, FMC BioProducts) and electrophoresed at $140 \mathrm{~V}$ for one hour. Then the gel will be stained in $1 \mu \mathrm{g} \mathrm{mL} \mathrm{m}^{-1}$ ethidium bromide solution for 10-15 min and visualized with UV light under Gel Documentation System (GDS) and the genotypes of each study subject for each polymorphism were determined accordingly (Fig. 1 and 2).

\section{Statistical Analysis}

The Statistical Package for the Social Science (SPSS for Windows) was used for statistical analysis. T-test was used for comparing the distribution of a variable between cases and controls groups. Genotypes and alleles distributions among the patients and controls were determined. The magnitude of the polymorphisms association with predisposing to human brucellosis was assessed by logistic regression analysis using SNPS tats for its penetrance in different genetic models of inheritance; allelic, co-dominant, dominant, over dominant and recessive models. Odds ratios will be calculated with 95\% confidence intervals using SNPS tats online software (http://bioinfo.iconcologia.net/snpstats/start.htm). $\mathrm{P}<0.05$ values were considered as significant.

\section{Results}

Sixty nine individuals with human brucellosis and 112 healthy individuals were selected for this casescontrol association study. Forty-five (65.2\%) of the patients were male and $24(34.8 \%)$ were female. The distribution of patients according their age is showing in Fig. 1 with an age mean of $42 \pm 22.17$ years. Fifty-two (75.4\%) were Saudi Arabian and the rest of the patients were from other different nationalities which are Sudanese 7(10.1\%), Egyptian 4(5.8\%), Pakistanian $4(5.8 \%)$ and Indian 2(2.95\%).

\section{Genotype and Allele Distributions in Brucellosis Patients and Healthy Subjects}

Genotyping of TNF- $\alpha-308 \mathrm{G}>\mathrm{A}$ and $-857 \mathrm{C}>\mathrm{T}$ polymorphism in both patients and healthy controls was done by PCR-RFLP method as showing in Fig. 2 and 3 respectively. The assessment of genotypes and allele frequencies of TNF- $\alpha-308 \mathrm{G}>\mathrm{A}$ and $-857 \mathrm{C}>\mathrm{T}$ polymorphisms are demonstrated for the subjects in both groups in Table 1 and Table 2 respectively. The distribution of each of genotypic variants met the conditions of Hardy-Weinberg equilibrium. For TNF- $\alpha-$ 308 gene polymorphism, The allele frequencies in control group $(n=112)$ were 0.83 for TNF- $\alpha-308 G$ (TNF1) and 0.17 for TNF $\alpha-308 \mathrm{~A}$ (TNF2) and the allele frequencies in 69 human brucellosis subjects were 0.83 for TNF- $\alpha-308 \mathrm{G}$ (TNF1) and 0.17 for TNF $\alpha$ 308A (TNF2). However, the distribution of TNF $\alpha-308$ genotypes and alleles did not differ significantly between patients and controls $(\mathrm{P}=0.116$ and $\mathrm{P}=$ 0.996 respectively) (Table 1 ). While, for $\mathrm{TNF} \alpha-857$ gene polymorphism, The allele frequencies in control group $(\mathrm{n}=112)$ were 0.91 for TNF- $\alpha-857 \mathrm{C}$ and 0.09 for TNF- $\alpha-857 \mathrm{~T}$ and the allele frequencies in 69 human brucellosis subjects were 0.93 for TNF $\alpha-857 \mathrm{C}$ and 0.07 for $T N F-\alpha-857 \mathrm{~T}$ with no significant differences in the genotypes and alleles frequencies between patients and controls $(\mathrm{P}=0.0 .640$ and $\mathrm{P}=$ 0.482 respectively) (Table 2 ).

Assessment of Effects of TNF $\alpha-308$ and -857 Gene Polymorphisms on Susceptibility to Human Brucellosis

The magnitude of the polymorphisms association with predisposing to human brucellosis in study population was assessed by logistic regression analysis using SNPS tats for its penetrance in different genetic models of inheritance; allelic, co-dominant, dominant, over dominant and recessive models (Table 1 and 2). Accordingly, the penetrance of TNF- $\alpha-308$ $\mathrm{G} / \mathrm{A}$ was more consistent with recessive genetic model rather than other genetic models $(\mathrm{OR}=3.003,95 \% \mathrm{CI}$ $0.278-5.702, \mathrm{P}=0.018)$. This indicates that having TNF- $\alpha-308 \mathrm{~A} / \mathrm{A}$ genotype is associated with high risk for human brucellosis under recessive genetic model in study population. While, for TNF- $\alpha-857 \mathrm{C}>\mathrm{T}$ gene polymorphism, as shown in Table 2, none of the tested genetic models was found to be consistent with its penetrance.

Results of statically test for deviation from HardyWeinberg equilibrium in control and infected cases of Brucella were presented in Table 3.

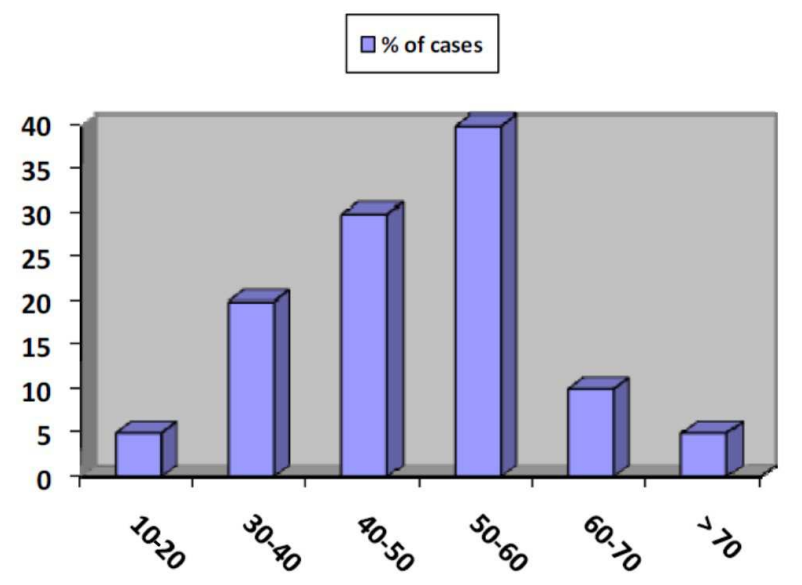

Fig. 1.Distribution of Brucella infected cases according to their age. The age mean is $42 \pm 22.17$ years 


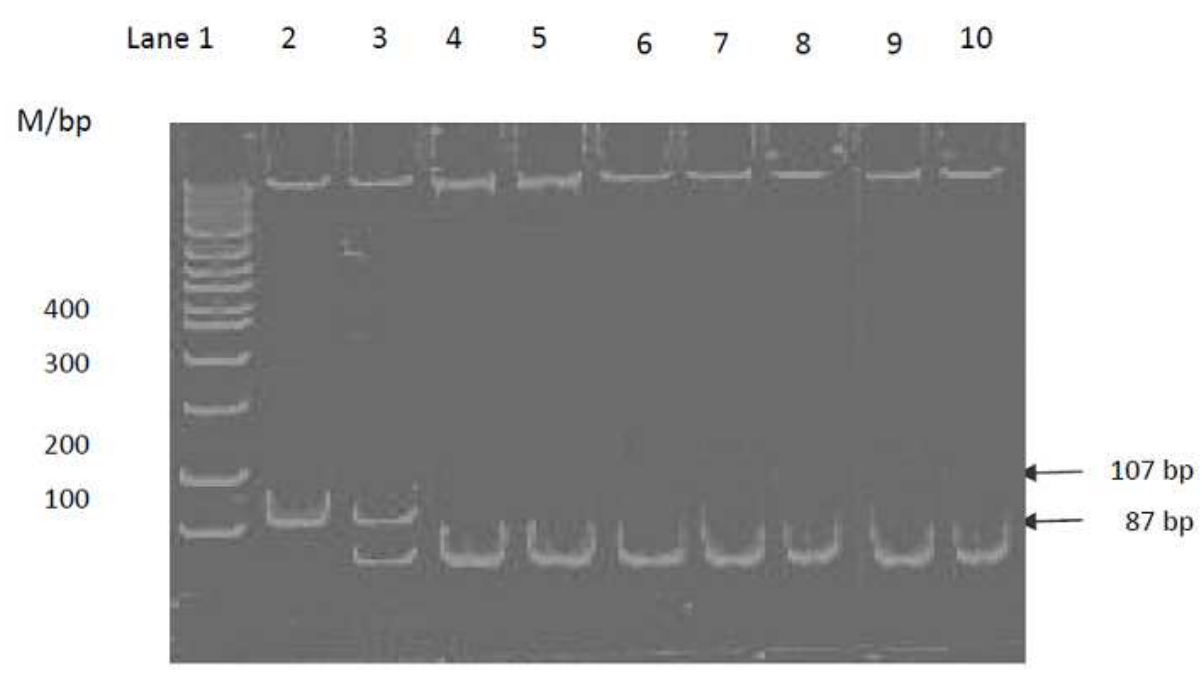

Fig. 2. Detection of TNF- $\alpha-308$ polymorphism using PCR-RFLP method Legand: Lane 1: M: 100-bp DNA marker. Lane 2: undigested PCR products. Lanes 3, 4, 5, 6, 7, 8, 9 and 10: Pateints 1-8 after NcoI digestion. Patients 2, 3, 4, 5, 67 and 8 are homozygous for TNF1; patients 1 is heterozygous TNF1/TNF2

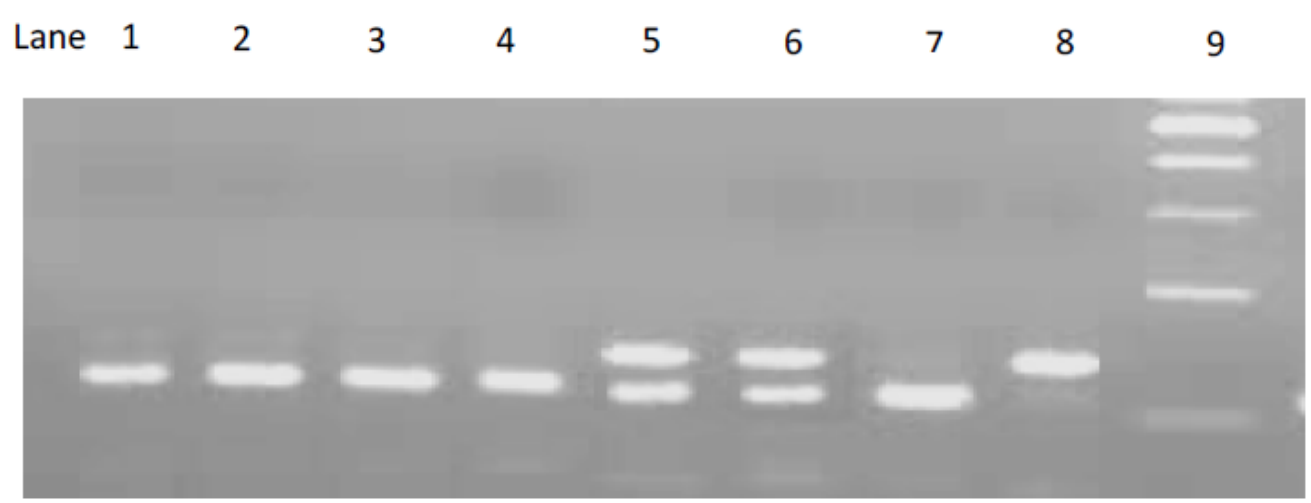

Fig. 3. Detection of TNF- $\alpha-857 \mathrm{C}>$ polymorphism using PCR-RFLP method Legand: Lane 9: M: 100-bp DNA marker. Lanes 1,2, 3,4 and 7 are homozygous wild type $(\mathrm{C} / \mathrm{C})$; Lanes 5 and 6 are heterozygous $(\mathrm{C} / \mathrm{T})$, while lane 8 is homozygous mutant $(\mathrm{T} / \mathrm{T})$ genotype

Table 1. Assessment of association of TNF- $\alpha-308 \mathrm{G}>\mathrm{A}$ polymorphism and brucellosis patients

\begin{tabular}{|c|c|c|c|c|}
\hline Model & Brucellosis patients $(n=69)$ & Healthy control $(\mathrm{n}=112)$ & $\mathrm{P}$ value (Pearson) & Odd ratio $(95 \% \mathrm{CI})$ \\
\hline \multicolumn{5}{|c|}{ Codominant } \\
\hline $\mathrm{G} / \mathrm{G}$ & $47(68 \%)$ & $74(66 \%)$ & 0.070 & 1.00 \\
\hline $\mathrm{G} / \mathrm{A}$ & $20(29 \%)$ & $37(33 \%)$ & & $1.50(0.540-4.170)$ \\
\hline $\mathrm{A} / \mathrm{A}$ & $2(3 \%)$ & $1(1 \%)$ & & $0.00(0.000-\mathrm{NA})$ \\
\hline \multicolumn{5}{|c|}{ Allelic effect } \\
\hline G & 0.83 & 0.83 & & \\
\hline A & 0.17 & 0.17 & 0.996 & $0.999(0.572-1.747)$ \\
\hline \multicolumn{5}{|c|}{ Overdominant } \\
\hline G/G-A/A & $49(71 \%)$ & $75(67 \%)$ & & 1.00 \\
\hline $\mathrm{G} / \mathrm{A}$ & $29(29 \%)$ & $37(33 \%)$ & 0.318 & $1.690(0.620-4.630)$ \\
\hline \multicolumn{5}{|l|}{ Recessive } \\
\hline $\mathrm{G} / \mathrm{G}-\mathrm{A} / \mathrm{G}$ & $67(97.1 \%)$ & $111(99.1)$ & & 1.00 \\
\hline $\mathrm{A} / \mathrm{A}$ & $2(2.9 \%)$ & $1(0.9 \%)$ & 0.018 & $3.222(1.008-5.702)$ \\
\hline \multicolumn{5}{|l|}{ Dominant } \\
\hline $\mathrm{G} / \mathrm{G}$ & $47(68.1 \%)$ & $74(66.1 \%)$ & & 1.00 \\
\hline $\mathrm{A} / \mathrm{G}-\mathrm{A} / \mathrm{A}$ & $22(31.9 \%)$ & $38(33.9)$ & 0.777 & $0.912(0.481-1.728)$ \\
\hline
\end{tabular}


Table 2. Assessment of association of TNF- $\alpha-857 \mathrm{C}>\mathrm{T}$ polymorphism and brucellosis patients

\begin{tabular}{|c|c|c|c|c|}
\hline Model & Brucellosis patients $(n=69)$ & Healthy control $(n=112)$ & $\mathrm{P}$ value (Pearson) & Odd ratio $(95 \% \mathrm{CI})$ \\
\hline \multicolumn{5}{|c|}{ Codominant } \\
\hline $\mathrm{C} / \mathrm{C}$ & $60(87 \%)$ & $94(83.9 \%)$ & 0.640 & 1.00 \\
\hline $\mathrm{C} / \mathrm{T}$ & $8(11.6 \%)$ & $15(13.4 \%)$ & & $1.48(0.270-8.121)$ \\
\hline $\mathrm{T} / \mathrm{T}$ & $1(1.4 \%)$ & $3(2.7 \%)$ & & $4.13(0.140-125.650)$ \\
\hline \multicolumn{5}{|c|}{ Allelic effect } \\
\hline $\mathrm{C}$ & 0.93 & 0.91 & & \\
\hline $\mathrm{T}$ & 0.07 & 0.09 & 0.482 & $0.755(0.345-1.655)$ \\
\hline \multicolumn{5}{|c|}{ Overdominant } \\
\hline $\mathrm{C} / \mathrm{C}-\mathrm{T} / \mathrm{T}$ & $61(88.4 \%)$ & $97(86.6 \%)$ & & 1.00 \\
\hline $\mathrm{C} / \mathrm{T}$ & $8(11.6 \%)$ & $15(13.4 \%)$ & 0.660 & $1.461(0.270-8.000)$ \\
\hline \multicolumn{5}{|l|}{ Recessive } \\
\hline $\mathrm{C} / \mathrm{C}-\mathrm{C} / \mathrm{T}$ & $68(98.6 \%)$ & $109(97.3 \%)$ & & 1.00 \\
\hline $\mathrm{T} / \mathrm{T}$ & $1(1.4 \%)$ & $3(2.7 \%)$ & 0.410 & $4.070(0.130-123.580)$ \\
\hline \multicolumn{5}{|l|}{ Dominant } \\
\hline $\mathrm{C} / \mathrm{C}$ & $60(87 \%)$ & $94(83.9 \%)$ & & 1.00 \\
\hline $\mathrm{C} / \mathrm{T}-\mathrm{T} / \mathrm{T}$ & $9(13 \%)$ & $18(16.1)$ & 0.443 & $1.82(0.391-8.410)$ \\
\hline
\end{tabular}

Table 3. Results of test for deviation from hardy-weinberg equilibrium in control and infected cases of brucella

\begin{tabular}{lll}
\hline SNP & Controls & Cases \\
\hline G308A of TNF- $\alpha$ & $\mathrm{n} 11=74(76.40)$ & $\mathrm{n} 11=47(47.09)$ \\
& $\mathrm{n} 12=37(32.21)$ & $\mathrm{n} 12=20(19.83)$ \\
$\mathrm{n} 22=1(3.40)$ & $\mathrm{n}(2.09)$ \\
& $\mathrm{n} 221=0.83 /+0.032$ \\
& $\mathrm{fa} 1=0.83 /+0.023$ & $\mathrm{~F}=0.00877$ \\
& $\mathrm{~F}=0.14872$ & $\mathrm{p}=0.941913$ (Pearson) \\
& $\mathrm{p}=0.115515$ (Pearson) & $\mathrm{p}=0.941657$ (Llr) \\
$\mathrm{p}=0.078250$ (L1r) & $\mathrm{p}=1.000000$ (Exact) \\
& $\mathrm{p}=0.186914$ (Exact) & $\mathrm{n} 11=60(59.36)$ \\
$\mathrm{n} 11=94(91.98)$ & $\mathrm{n} 12=8(9.28)$ \\
& $\mathrm{n} 12=15(19.03)$ & $\mathrm{n} 22=1(0.36)$ \\
& $\mathrm{n} 22=3(0.98)$ & fa1 $=0.93+/ 0.024$ \\
& $\mathrm{fa} 1=0.91+/ 0.021$ & $\mathrm{~F}=0.13750$ \\
& $\mathrm{~F}=0.21182$ & $\mathrm{p}=0.253387$ (Pearson) \\
& $\mathrm{p}=0.024979$ (Pearson) & $\mathrm{p}=0.330758$ (Llr) \\
& $\mathrm{p}=0.057079$ (Llr) & $\mathrm{p}=0.295670$ (Exact) \\
\hline
\end{tabular}

n11 (e): Genotype 11 (expected); n12 (e): Genotype 12 (expected); n22 (e): Genotype 22 (expected); f a1: Frequency of allele $1+$ /standard deviation; F: Inbreeding coefficient; $p$ (Pearson): Pearson's goodness-of-fit chisquare (degree of freedom $=1) ; \mathrm{p}$ $(\mathrm{Llr})$ : Log likelihood ratio chisquare (degree of freedom $=1)$; $\mathrm{p}($ Exact): Exact test

\section{Discussion}

Cytokines play a key role in the regulation of the immune response and the capacity of cytokine production differs among individuals and correlates with the polymorphism in the cytokine gene promoters (Ben-Ari et al., 2003). Host resistance to Brucella has been mainly studied in mice and shown that cytokines control the immune response and influence the outcome of the disease (Baldwin and Parent, 2002). Although few studies in human, patients with acute brucellosis display a Th1-type response in contrast to those with chronic form who have diminished Th1 response in response to the Brucella specific antigens (Giambartolomei et al., 2002). Polymorphisms affecting cytokines controlling the immune response against infectious diseases could be the potential markers of susceptibility and clinical outcome of different infectious diseases in humans (Hajilooi et al., 2006). In this study, we assessed the potential associations and their mode of penetrance between two polymorphisms in TNF- $\alpha$ gene promoter $(-308 \mathrm{G} / \mathrm{A}$ and $-857 \mathrm{C} / \mathrm{T}$ ) and human brucellosis. We found no significant association for TNF- $\alpha-857$ gene polymorphism under any of the five tested genetic models. Although, we demonstrated an increased risk for human brucellosis associated with homozygosity of TNF- $\alpha-308$ A allele and this association is consistent with the recessive genetic model rather than other tested models.

Our findings indicate no association between susceptibility of human brucellosis and TNF- $\alpha-857$ $\mathrm{C} / \mathrm{T}$ polymorphism. Although, TNF- $\alpha-857 \mathrm{~T}$ allele frequency was found to be higher in the healthy control (0.09) than in brucellosis cases (0.07). Nerveless, the proportion of genotypes carrying TNF- 
$\alpha-857 \mathrm{~T}$ allele in healthy control group $(0.16)$ either in heterozygous state (CT) or homozygous (TT) compared to their proportion in brucellosis cases (0.13) seem to have a protective effect against the disease. However, the difference was not statistically significant $(\mathrm{P}=0.443$, OR: $1.82,95 \% \mathrm{CI}: 0.391$ 8.410). Thus, our result suggests nonexclusive protective role of $\mathrm{TNF}-\alpha-857 \mathrm{C} / \mathrm{T}$ polymorphism against human brucellosis in this study population.

Considering TNF- $\alpha-308 \mathrm{G} / \mathrm{A}$ polymorphism, although, the TNF2 allele was found to be at similar frequency of $(0.17)$ in both brucellosis patients and healthy control, our findings indicated an increased risk TNF- $\alpha-308$ A allele for human brucellosis consistent with the recessive genetic model of penetrance (Odd Ratio: 3.222 , 95\% CI: 1.008-5.702, P = 0.018). Similar results were reported by Eskandari-Nasab and his colleagues who stated that the TNF- $\alpha-308$ A allele or GA heterozygosity were associated with an increased risk of brucellosis (Eskandari-Nasab et al., 2016). Furthermore, few other studies showed a significant association between the TNF- $\alpha-308$ (A/A) genotype and brucellosis (Caballero et al., 2000b; Davoudi et al., 2006; Reza et al., 2009). This finding is not consistent with the results reported by few studies in which TNF2 allele revealed no association with human brucellosis (Karaoglan et al., 2009).

In this study, the relatively lower frequency of homozygozity for TNF2 in control group (0.009) may be either due to relatively smaller sample size (181) as according to TNF- $\alpha-308 \mathrm{~A}$ allele frequency (0.17), homozygosity was expected at a frequency of 0.029 or may be due to a strong negative selective pressure for this allele as children who are homozygote for this allele may be more susceptible to several severe infectious diseases endemic in the region and most probably may die at younger age and rarely reach reproductive age (Mergani et al., 2010). Further, the maintenance of high prevalence of the TNF- $\alpha-308 \mathrm{~A}$ allele frequency in this study population (0.17) suggests a heterozygote advantage. Possibly the TNF2 allele in homozygote status leads to increased constitutive expression of TNF- $\alpha$ which could be harmfull to patients (Wilson et al., 1997; Abraham and Kroeger, 1999). TNF- $\alpha$ might enhance disease either directly or through over-stimulation of the cytokine cascade (Clark et al., 1989). However, in heterozygote, the expression of TNF- $\alpha$ may be more balanced than both homozygote TNF1 or TNF2 and may confer protective measures against several other infectious diseases. This explanation is supported by the observation in study in Tanzania where infants who were heterozygous for the TNF- $\alpha-308$ polymorphism appeared to have fewer febrile episodes when they were free of malaria parasites (Stirnadel et al., 1999).

\section{Conclusion}

Our findings indicate an increased risk of TNF- $\alpha-$ 308A allele for human brucellosis consistent with the recessive genetic model of penetrance. Moreover, a protective role of $\mathrm{TNF}-\alpha-857 \mathrm{C} / \mathrm{T}$ polymorphism against human brucellosis in this study population could not be excluded.

\section{Acknowledgement}

The authors wish to extend their gratitude to the Vice President for Post-graduate Studies and Research, Taif University for providing research facilities.

\section{Funding Information}

This work is funded by the Deanship of Scientific Research, Taif University under the Fundamental Research Grant No. 1/ 436 /4294.

\section{Author's Contributions}

Alaa B. Ismael: Contributed to conception and design, carrying out the PCR-RFLP with the coworkers and critically revised manuscript with its submission.

Adil Mergani: Contributed to design, acquisition, carrying out the PCR-RFLP with the coworkers, interpretation, data analysis and draft and revised manuscript.

Salama A-H Mostafa: Participate in laboratory experiments and manuscript revision.

Abdelmoneim M. Salim: Collection of samples, perform gel agarose analysis and manuscript revision.

\section{Conflicts of Interest}

The authors declare that they have no conflicts of interest.

\section{References}

Abraham, L.J. and K.M. Kroeger, 1999. Impact of the 308 TNF promoter polymorphism on the transcriptional regulation of the TNF gene: Relevance to disease. J. Leukoc. Biol., 66: 562-566.

Adrian, V. and S. Hill, 1998. The immunogenetics of human infectious diseases. Ann. Rev. Immunol. Invest., 16: 593-617.

DOI: 10.1146/annurev.immunol.16.1.593

Arrighi, H.M., 1986. Brucellosis surveillance in Saudi Arabia's Eastern Province. Ann. Saudi Med., 6: 5-10.

Baldwin, C.L. and M. Parent, 2002. Fundamentals of host immune response against Brucella abortus: What the mouse model has revealed about control of infection. Vet. Microbiol., 90: 367-382. DOI: $10.1016 / \mathrm{S} 0378-1135(02) 00222-5$ 
Ben-Ari, Z., E. Mor, O. Papo, B. Kfir and J. Sulkes et al., 2003. Cytokine gene polymorphisms in patients infected with hepatitis B virus cito kine gene polymorphisms and HBV. Am. J. Gastroenterol., 98: 144-150. DOI: 10.1111/j.1572-0241.2003.07179.x

Benjamin, B. and S.H. Annobil, 1992. Childhood brucellosis in southwestern Saudi Arabia: A 5-year experience. J. Trop. Pediatr., 38: 167-172.

DOI: $10.1093 /$ tropej/38.4.167

Bidwell, J., L. Keen, G. Gallagher, R. Kimberly and M.F. McDermott et al., 1999. Cytokine gene polymorphism in human disease: On-line databases. Genes Immunity, 1: 3-19.

DOI: $10.1038 /$ sj.gene. 6363645

Bidwell, J., L. Keen, G. Gallagher, L. Kimberly and T. Huizinga et al., 2001. Cytokine gene polymorphism in human disease: On-line databases. Genes Immunity, 2: 61-70.

DOI: $10.1038 /$ sj.gene. 6363733

Caballero, A., M.J. Bravo, J.D. Nieto, J.D. Colmenero and A. Alonso et al., 2000. TNFa promoter polymorphism and susceptibility to brucellosis. Clin. Exp. Immunol., 121: 480-483. DOI: $10.1046 /$ j.1365-2249.2000.01331.x

Caballero, A., M.J. Bravo, A. Nieto, J.D. Colmenero and A. Alonso et al., 2000. TNFA promoter polymorphism and susceptibility to brucellosis. Clin. Exp. Immunol., 121: 480-483.

DOI: $10.1046 / \mathrm{j} .1365-2249.2000 .01331 . x$

Clark, I.A., G. Chaudhri and W.B. Cowden, 1989. Roles of tumour necrosis factor in the illness and pathology of malaria. Trans. R. Soc. Trop. Med. Hyg., 83: 436-440. DOI: 10.1016/0035-9203(89)90240-X

Corbel, M.J., 1997. Brucellosis: An overview. Emerg. Infect. Dis., 3: 213-221.

DOI: $10.3201 /$ eid0302.970219

Davoudi, S., A.A. Amirzargar, M. Hajiabdolbaghi, M. Rasoolinejad and A. Soodbakhsh et al., 2006. Th-1 cytokines gene polymorphism in human brucellosis. Int. J. Immunogenet., 33: 355-359. DOI: 10.1111/j.1744-313X.2006.00626.X

Dornand, J., A. Gross, V. Lafont, J. Liautard and J. Oliaro et al., 2002. The innate immune response against Brucella in humans. Vet. Microbiol., 90: 383-394. DOI: 10.1016/S0378-1135(02)00223-7

Eskandari-Nasab, E., M. Moghadampour and A. Sepanj-Nia, 2016. TNF-alpha -238, -308, -863 polymorphisms and brucellosis infection. Hum. Immunol., 77: 121-125.

DOI: 10.1016/j.humimm.2015.11.010

Fargion, S., L. Valenti, P. Dongiovanni, A. Scaccabarozzi and A.L. Fracanzani et al., 2001. Tumor necrosis factor alpha promoter polymorphisms influence the phenotypic expression of hereditary hemochromatosis. Blood, 97: 3707-3712.

DOI: $10.1182 /$ blood.V97.12.3707
Ficht, T.A., 2003. Intracellular survival of Brucella: defining the link with persistence. Vet. Microbiol., 92: 213-223. DOI: $10.1016 / \mathrm{S} 0378-1135(02) 00367-\mathrm{X}$

Giambartolomei, G.H., M.V. Delpino, M.E. Cahanovich, J.C. Wallach and P.C. Baldi et al., 2002. Diminished production of $\mathrm{T}$ helper 1 cytokines correlates with $\mathrm{T}$ cell unresponsiveness to Brucella cytoplasmic proteins in chronic human brucellosis. J. Infect. Dis., 186: 252-259. DOI: $10.1086 / 341449$

Hafez, S.M., 1986. The impact of uncontrolled animal importation and marketing on the prevalence of brucellosis in Saudi Arabia. Ann. Saudi Med., 6: 515-518.

Huang, L.Y., K.J. Ishii, S. Akira, J. Aliberti and B. Golding, 2005. Th1-like cytokine induction by heat-killed Brucella abortus is dependent on triggering of TLR9. J. Immunol., 175: 3964-3970. DOI: 10.4049/jimmunol.175.6.3964

Janeway Jr., C.A. and R. Medzhitov, 2002. Innate immune recognition. Annu. Rev. Immunol., 20: 197-216. DOI: 10.1146/annurev.immunol.20.083001.084359

Jiang, X. and C.L. Baldwin, 1993. Effects of cytokines on intracellular growth of Brucella abortus. Infect. Immun., 61: 124-134.

Jiang, X., B. Leonard, R. Benson and C.L. Baldwin, 1993. Macrophage control of Brucella abortus: Role of reactive oxygen intermediates and nitric oxide. Cell Immunol., 151: 309-319.

DOI: $10.1006 /$ cimm.1993.1241

Kambal, A.M., E.S. Mahgoub, G.A. Jamjoom and M.N. Chowdhury, 1983. Brucellosis in Riyadh, Saudi Arabia. A microbiological and clinical study. Trans. R. Soc. Trop. Med. Hyg., 77: 820-824. DOI: 10.1016/0035-9203(83)90297-3

Karaoglan, I., S. Pehlivan, M. Namiduru, M. Pehlivan and C. Kilincarslan et al., 2009. TNF-alpha, TGF-beta, IL-10, IL-6 and IFN-gamma gene polymorphisms as risk factors for brucellosis. New Microbiol., 32: 173-178. PMID: 19579695

Madkour, M.M., M.A.S. Talukdar and A.J.N. Kudwah, 1985. Brucellosis in Saudi Arabia. Saudi Med. J., 6: 324-332.

Mergani, A., A.H. Khamis, A.B. Haboor, E. Hashim and M. Gumma et al., 2010. Lack of association between-308 tumor necrosis factor polymorphism and susceptibility to cerebral malaria among Central Sudanese children. Int. J. Gene. Mol. Bio., 2: 67-71.

Murphy, E.A., J. Sathiyaseelan, M.A. Parent, B. Zou and C.L. Baldwin, 2001. Interferon- $\gamma$ is crucial for surviving a Brucella abortus infection in both resistant $\mathrm{C} 57 \mathrm{BL} / 6$ and susceptible $\mathrm{BALB} / \mathrm{c}$ mice. Immunology, 103: 511-518.

DOI: $10.1046 / \mathrm{j} .1365-2567.2001 .01258 . \mathrm{x}$ 
Oliveira, S.C. and G.A. Splitter, 1995. CD8+ type 1 CD44hi CD45Rblo $\mathrm{T}$ lymphocytes control intracellular Brucella abortus infection as demonstrated in major histocompatibility complex class I- and Class II deficient mice. Eur. J. Immunol., 25: 2551-2557. DOI: 10.1002/eji.1830250922

Pappas, G. and Z.A. Memish, 2007. Brucellosis in the middle East: A persistent medical, socioeconomic and political issue. J. Chemother., 19: 243-248. DOI: 10.1179/joc.2007.19.3.243

Reza, J.S., R. Alireza, A. Mostafa, K. Alireza and H. Mehrdad, 2009. Association of tumor necrosis factor-alpha-308 (G-->A) polymorphism and susceptibility to brucellosis. J. Microbiol. Immunol. Infect., 42: 22-26.

Rodriguez-Zapata, M., M.J. Matías, A. Prieto, M.A. Jonde and J. Monserrat et al., 2010. Human brucellosis is characterized by an intense Th1 profile associated with a defective monocyte function. Infect. Immun., 78: 3272-3279.

DOI: $10.1128 /$ IAI.01385-09
Soga, Y., F. Nishimura, H. Ohyama, H. Maeda and S. Takashiba et al., 2003. Tumor necrosis factoralpha gene (TNF-alpha) -1031/-863, -857 SingleNucleotide Polymorphisms (SNPs) are associated with severe adult periodontitis in Japanese. J. Clin. Periodontol., 30: 524-531.

DOI: 10.1034/j.1600-051X.2003.00287.x

Stirnadel, H.A., M. Stockle, I. Felger, T. Smith and M. Tanner et al., 1999. Malaria infection and morbidity in infants in relation to genetic polymorphisms in Tanzania. Trop. Med. Int. Health, 4: 187-193. DOI: 10.1046/j.1365-3156.1999.43381.x

Wilson, A.G., J.A. Symons, T.L. McDowell, H.O. McDevitt and G.W. Duff, 1997. Effects of a polymorphism in the human tumor necrosis factor alpha promoter on transcriptional activation. Proc. Natl. Acad. Sci., USA, 94: 3195-3199. DOI: $10.1073 /$ pnas.94.7.3195

Zhan, Y., J.I. Yang and C. Cheers, 1993. Cytokines response of T-cell subsets from Brucella abortus infected mice to soluble Brucella proteins. Infect. Immun., 61: 2841-2847. 